\title{
The Challenges Of Using Multicomputing IN REAL TIME VISUALAPPLICATIONS
}

\author{
AlaaYaseenTaqa ${ }^{1}$,LiangShing $\mathrm{Ng}^{2}$ and Ajay Anant $\mathrm{Joshi}^{3}$ \\ ${ }^{1}$ Computer Science Dep./Mosul University/IRAQ \\ alaa.taqa@gmail.com \\ ${ }^{2}$ Faculty of Computer Science \& Information Technology, University of Malaya \\ lsng@um.edu.my \\ ${ }^{3}$ Dep.Electrical and Computer Engineering/ University of the West Indies \\ Ajay.Joshi@sta.uwi.edu
}

\begin{abstract}
Displaying visual data in a graphical distributed application is one of the main challenges and constraints that should be studied in real time applications. Many problems could be reported in using multicomputing for real time visual applications. These problems are identified throughout this survey, and are classified into two main categories. The first is computation and transfer time while the second is display speed. The real bottleneck in using grid or cloud computing in such applications is whether the communication time between nodes (inside the cloud) increases to the point of degrading overall application performance. This survey paper describes the impact of time and communication speed on applying visual systems on a grid or in cloud computing.
\end{abstract}

\section{KEYWORDS}

Multi Computing, Cloud Computing, Grid Computing, Visualization and Virtualization

\section{INTRODUCTION}

Managing (controlling) parallel applications is difficult, and is based on communication and synchronization between different subtasks. It involves extracting information about the interaction and collection among process units, preparing it in useful formats, and then displaying information on interactions among concurrently executing processes.Displaying visual data in a graphical distributed application is one of the main challenges and constraints that should be studied. The interactive computer graphics architecture was developed through four generations over the past two decades. Not only has the performance improvement of computer graphics hardware exceeded Moore's Law, modern computer graphics hardware also possesses more transistors than modern central processing units (CPUs) do. However, many applications, such as scientific visualization of large data sets, high-resolution display, and photo-realistic rendering, still cannot run in real-time on high-end modern graphics hardware [1]. In this paper, several grid topologies used in different visual applications will be analyzed to describe the impact of time and communication speed on applying visual systems on a grid or in cloud computing.

\section{MULTI-COMPUTING}

A distributed application consists of multiple autonomous computers that communicate through a computer network. These computers interact with each other to perform a common goal [2]. Parallel computing could be defined as a form of computation in which many calculations are executed simultaneously [3]. It is easy to derive an integrative definition as well as a minimum common denominator. Grid computing refers to servers collecting and working together to

DOI : $10.5121 /$ ijcses.2011.2401 
perform a single task. Cloud computing is the convergence and evolution of several concepts such as virtualization, distributed application design, grid, and enterprise IT management, to enable a more flexible approach for deploying and scaling applications [4]. Most available definitions of multi-computing (grids and cloud computing) are in Tables 1 and 2, respectively.One of the main challenges in cloud computing is interconnecting remote sites at the lowest possible cost of ownership. The success of the cloud computing business is strongly dependent on cost-effective service offerings, which compete heavily with traditional local implementations [19].

Table 1. Grid Computing Definitions

\begin{tabular}{l|l}
\hline Reference/Author/Year & \multicolumn{1}{c}{ Definition } \\
\hline \multirow{5}{*}{ [5] Foster et al. 2001 } & $\begin{array}{l}\text { "Grid" computing has emerged as an important new field, } \\
\text { distinguished from conventional distributed computing by } \\
\text { its focus on large-scale resource sharing, innovative } \\
\text { applications, and, in some cases, high-performance } \\
\text { orientation. }\end{array}$ \\
\hline [6] Adabala et al. 2005 & $\begin{array}{l}\text { Information "grids" promise to revolutionize scientific } \\
\text { computing and information processing by enabling access } \\
\text { to unprecedented computing power and functionality of } \\
\text { diverse interconnected computers, geographically } \\
\text { distributed software applications and other network- } \\
\text { accessible resources }\end{array}$ \\
\hline [7] Jacob et al. 2005 & $\begin{array}{l}\text { It isany variety of levels of virtualization along a } \\
\text { continuum. Exactly where along that continuum one might } \\
\text { [9] Linesch ] 2007 }\end{array}$ \\
\hline [8] Lakshmi and \\
Ravichandran 2006
\end{tabular}


International Journal of Computer Science \& Engineering Survey (IJCSES) Vol.2, No.4, November 2011

Table 2. Cloud Computing Definitions

\begin{tabular}{|c|c|}
\hline Reference/Author/Year & Definition \\
\hline [11] Bechtolsheim 2008 & $\begin{array}{l}\text { The fifth generation of Computing (after Mainframe, Personal } \\
\text { Computer, Client-Server Computing, and the web) }\end{array}$ \\
\hline [12] Armbrust et al. 2009 & $\begin{array}{l}\text { It refers to both the applications delivered as services over the } \\
\text { Internet and the hardware and applications software in the } \\
\text { datacenters that provide those services }\end{array}$ \\
\hline [13] Gillis 2009 & $\begin{array}{l}\text { It is the provision of dynamically scalable and often virtualized } \\
\text { resources as a service }\end{array}$ \\
\hline [14] F5 Networks 2009 & $\begin{array}{l}\text { It is a style of computing in which dynamically scalable and } \\
\text { often virtualized resources are provided as a service over the } \\
\text { Internet. Users need not have knowledge of, expertise in, or } \\
\text { control over the technology infrastructure in the "cloud." }\end{array}$ \\
\hline [15] Vaquero et al. 2009 & $\begin{array}{l}\text { Clouds are a large pool of easily usable and accessible } \\
\text { virtualized resources (such as hardware, development platforms } \\
\text { and/or services). These resources can be dynamically re- } \\
\text { configured to adjust to a variable load (scale), allowing also for } \\
\text { an optimum resource utilization. This pool of resources is } \\
\text { typically exploited by a pay- per-use model in which guarantees } \\
\text { are offered by the Infrastructure Provider by means of } \\
\text { customized SLAs. }\end{array}$ \\
\hline [16] Mell and Grance 2009 & $\begin{array}{l}\text { It is a model for enabling convenient, on-demand network } \\
\text { access to a shared pool of configurable computing resources } \\
\text { (e.g., networks, servers, storage, applications, and services) that } \\
\text { can be rapidly provisioned and released with minimal } \\
\text { management effort or service provider interaction. This cloud } \\
\text { model promotes availability and is composed of five essential } \\
\text { characteristics, three service models, and four deployment } \\
\text { models. }\end{array}$ \\
\hline [17] Buyya et al. 2009 & $\begin{array}{l}\text { It is a type of parallel and distributed system consisting of a } \\
\text { collection of inter-connected and virtualized computersthat are } \\
\text { dynamically provisioned and presented as one or more unified } \\
\text { computing resource(s) based on service-level agreements } \\
\text { established through negotiation between the service provider } \\
\text { and consumers.' }\end{array}$ \\
\hline [18] MacVittie et al.2010 & $\begin{array}{l}\text { The cloud is simply an architectural model that employs many } \\
\text { of the same components used in datacenters around the world } \\
\text { today in a more flexible, responsive, and efficient way. }\end{array}$ \\
\hline
\end{tabular}

\section{CLOUD COMPUTING APPLICATIONS}

Many people are confused on the definition of cloud computing, especially as the term can applied to many things. However, it means making computations through the Internet, from which all resources can be accessed without worrying about resource maintenance or management. [16] discussed the concept of cloud computing to achieve a complete definition of the cloud, and described the relationships and distinctions between grid and cloud approaches.

The University of California (UC) Berkeley Reliable Adaptive Distributed Systems Laboratory [13] stated that cloud computing refers to applications delivered as services over the Internet, and the hardware and systems software in the datacenters that provide these services. They tried to identify the top technical and non-technical obstacles and opportunities in cloud computing. Their view is shaped in part by working since 2005 in the UC Berkeley RAD Lab and in part as 
users of Amazon Web Services since January 2005 They spent six months brainstorming about cloud computing, leading to their main 10 obstacles and opportunities for cloud computing in Table 3. The review of Table 3 does not mention the obstacles on applying visual application in cloud computing.

Table 3. Quick Preview of Top 10 Obstacles to and Opportunities for Growth of Cloud Computing [13]

\begin{tabular}{l|l|l}
\hline & \multicolumn{1}{|c}{ Obstacle } & \multicolumn{1}{c}{ Opportunity } \\
\hline 1 & Availability of Service & $\begin{array}{l}\text { Use Multiple Cloud Providers; Use } \\
\text { Elasticity to Prevent DDOS }\end{array}$ \\
\hline 2 & Data Lock-In & $\begin{array}{l}\text { Standardize APIs; Compatible SW to } \\
\text { enable Surge Computing }\end{array}$ \\
\hline 3 & $\begin{array}{l}\text { Data Confidentiality and } \\
\text { Auditability }\end{array}$ & $\begin{array}{l}\text { Deploy Encryption, VLANs, Firewalls; } \\
\text { Geographical Data Storage }\end{array}$ \\
\hline 5 & Data Transfer Bottlenecks & $\begin{array}{l}\text { FedExing Data } \\
\text { Backup/Archival; Higher BW Switches }\end{array}$ \\
\hline 6 & Performance Unpredictability & $\begin{array}{l}\text { Improved VM Support; Flash Memory; } \\
\text { Gang Schedule VMs }\end{array}$ \\
\hline 8 & $\begin{array}{l}\text { Bugs in Large Distributed } \\
\text { Systems }\end{array}$ & $\begin{array}{l}\text { Invent Debugger that relies on } \\
\text { Distributed VMs }\end{array}$ \\
\hline 9 & Scaling Quickly & $\begin{array}{l}\text { Invent Auto-Scaler that relies on ML; } \\
\text { Snapshots for Conservation }\end{array}$ \\
\hline 10 & Seputation Fate Sharing & $\begin{array}{l}\text { Offer reputation-guarding services like } \\
\text { those for email }\end{array}$ \\
\hline
\end{tabular}

Buyya et al. [20] introduced CloudSim, which is an extensible simulation toolkit that enables modeling and simulation of cloud computing environments. The CloudSim toolkit supports modeling and creating one or more virtual machines (VMs) on a simulated node of a datacenter, jobs, and their mapping to suitable VMs. The authors did not specify the application type used in testing the toolkit and did not evaluate using it with visual applications. ElasTraS was proposed by [21], which addresses the issue of scalability and elasticity of data stored in a cloud computing environment to leverage the elastic nature of the underlying infrastructure, while providing scalable transactional data access. The review of [21] does not mention visual data, which could be stored in the cloud.

Many Web applications need strong data consistency for correct execution. However, although the high scalability and availability of the cloud makes it a good platform to host Web content, scalable cloud database services provide relatively weak consistency properties. Wei at al. [22] showed how one can support Atomicity, Consistency, Isolation, Durability(ACID) transactions without compromising the scalability of the cloud for Web applications, even in the presence of server failures and network partitions.

A review of cloud computing applications shows that no paper until this study has focused on the obstacles of applying visual applications using cloud computing.

\section{GRID COMPUTING APPLICATIONS}

Grids today appear mostly in high-performance computing environments, where many inexpensive compute nodes link to solve parallel processing problems that previously could only have been addressed by using supercomputers. Seventeen up-to-date papers (Table 4) were collected as a sample of using grid computing in different applications. The applications, 
topologies, and problems of these samples will be discussed in the next section. Many parallel problems could be solved using grid computing. It plays an important role in applications that need visual (graphics and images) rendering. Table 5 summarizes the applications in the papers listed in Table 4. Each application uses a different grid computing topology (Table 6) that determines the number of process units and display specifications in addition to the software used in grid application construction.

Table 5. The Applications List

\begin{tabular}{|c|c|}
\hline Reference & Application \\
\hline [23] & Medical image processing \\
\hline [24] & Medical image retrieval \\
\hline [25] & Remote sensing images \\
\hline [26] & $\begin{array}{l}\text { SWAP (Soil Water Atmosphere and Plant) crop model and } \\
\text { the Remote Sensing (RS) }\end{array}$ \\
\hline$[27]$ & $\begin{array}{l}\text { Parallel data mining that utilizes new-generation graphics } \\
\text { processing units (GPUs). }\end{array}$ \\
\hline [28] & $\begin{array}{l}\text { Parallel interactive applications MPI fluid simulation real- } \\
\text { time 3D modeling }\end{array}$ \\
\hline [29] & $\begin{array}{l}\text { Studding the strong scaling of the graphics application at } \\
\text { high resolution ( } 17.6 \text { Megapixels) with advanced lighting, } \\
\text { scientific data set }\end{array}$ \\
\hline$[30]$ & Video stream MPEG \\
\hline [31] & $\begin{array}{l}\text { The parallel scientific applications are } 3 \mathrm{D} \text { parallel volume } \\
\text { rendering application and } 2 \mathrm{D} \text { high resolution imagery } \\
\text { application }\end{array}$ \\
\hline [32] & Grid Online Game Jake2 \\
\hline$[33]$ & Graphical Geographic information applications \\
\hline [34 ] & Multiscreen display applications \\
\hline [35] & Large scale volume data (Image) \\
\hline [36] & $\begin{array}{l}\text { General graphics } 3 \mathrm{~d} \text { and } 2 \mathrm{~d} \text { Ant Colony Optimization is } \\
\text { used in rendering (solving scheduling problems). }\end{array}$ \\
\hline [37] & Magnetohydrodynamics \\
\hline [38 ] & Medical image \\
\hline [39] & $\begin{array}{l}\text { It describes how the computational steering and online } \\
\text { visualization with the covs framework implementation can } \\
\text { be used within todays Grid and e-science infrastructures. }\end{array}$ \\
\hline
\end{tabular}

The main problems facing parallel applications are computation and transfer time. Creating applications to run on a grid is more difficult than creating a large monolithic custom application for a dedicated supercomputer.Most people currently working on grid computing focus on the challenges of its physical operations, such as determining available computer and database resources, and organizing them into a functioning application. However, the most important thing to focus on is time. Grid application coordination requires a list of available computer nodes, performance characteristics, communication time, display specifications, computation time, and complexity of problem parts. Grid application coordinators utilize this information to configure the grid by calculating the optimal number of computer nodes or processors, partitioning the problem, and distributing these parts to obtain the best possible performance regardless of grid used. These measurements enable the application's autonomic program manager, which serves as the application coordinator, to reassign problem parts among grid 
International Journal of Computer Science \& Engineering Survey (IJCSES) Vol.2, No.4, November 2011

nodes and make other needed adjustments. Table 6 shows the hardware specifications and the necessary time for each application listed in Table 5.

\begin{tabular}{|c|c|c|}
\hline \multicolumn{3}{|c|}{ Table 6. Specification and Execution Time } \\
\hline Reference & \begin{tabular}{|c|} 
Number of processors \\
\end{tabular} & Time \\
\hline$[36]$ & $\begin{array}{l}\text { For testing purpose } 7 \text { homogeneous grid nodes } \\
2 \text { nodes ( Inter Xeon } 30401.86 \mathrm{G}, 1024 \text { memory, } \\
\text { Windows XP) } \\
2 \text { nodes (Inter Celeron 2.00GHZ,1024 memory } \\
\text {,Windows Vista) } \\
3 \text { nodes (Inter Core } 2 \text { double Extreme E7200,1536 } \\
\text { memory, Windows 2000) }\end{array}$ & $\begin{array}{l}19 \text { minutes for } \\
50 \quad \text { slice } \\
\text { rendering }\end{array}$ \\
\hline$[25]$ & 4 computers a processing node & $\begin{array}{l}2868 \mathrm{~ms} \text { for } 4 \\
\mathrm{M} \text { data } \\
\text { segmentation } \\
\text { by OTSU }\end{array}$ \\
\hline [26] & $\begin{array}{l}1 \text { computation node } \\
2 \\
15 \\
\text { Single site only }\end{array}$ & $\begin{array}{l}17,382 \mathrm{sec} \\
9,276 \mathrm{sec} \\
1,218 \mathrm{sec} \\
\begin{array}{l}\text { Pixel based } \\
\text { data }\end{array} \\
\end{array}$ \\
\hline$[34]$ & 6 nodes & $\begin{array}{lr}18.3 & \text { read } \\
\text { write } & \text { and } \\
\text { transmit } & \\
& \\
31.0 \mathrm{~ms} & \\
\end{array}$ \\
\hline [27] & $\begin{array}{l}\text { 30 SIMD /8 processors The CPU has } 4 \text { cores running at } \\
2.4 \mathrm{GHZ}\end{array}$ & $\begin{array}{l}23.8255 \mathrm{sec} . / \\
\text { data size } 400 \mathrm{k}\end{array}$ \\
\hline$[35]$ & $\begin{array}{l}12 \text { agents with } 3 \text { types of computing powers (low, } \\
\text { medium and high) only } 54.2 \% \text { agents utilization }\end{array}$ & $\begin{array}{lr}10000 & \text { second } \\
/ 100 & \text { sub } \\
\text { volume of data }\end{array}$ \\
\hline$[31]$ & $\begin{array}{l}32 \text { node / } 1 \text { process per node } \\
32 \text { node / } 2 \text { process per node } \\
\text { The data size is } 2 \text { to power } 27\end{array}$ & $\begin{array}{l}1475.37 \mathrm{sec} \\
1892.42 \mathrm{sec}\end{array}$ \\
\hline [28] & $\begin{array}{l}\text { Flat data flow graph of the acquisition component for } \\
6 \text { cameras ( } 50 \text { nodes and } 68 \text { edges) Flat data flow } \\
\text { graph of the acquisition component for } 6 \text { cameras and a } \\
\text { supervision interface ( } 105 \text { nodes and } 176 \text { edges) }\end{array}$ & $\begin{array}{l}30 \text { images per } \\
\text { second }\end{array}$ \\
\hline [29] & 6144 processor & $\begin{array}{l}11.5268 \\
\text { second } \\
\text { Scene, Parsing } \\
\text { Preprocess } \\
\text { Ray, Tracing, } \\
\text { Image I/O }\end{array}$ \\
\hline [39] & 65536 processors & $\begin{array}{l}\text { No mentioned } \\
\text { to time } \\
\mathrm{O}(\mathrm{n} \log n)\end{array}$ \\
\hline [37] & $\begin{array}{l}128 X 1 X 1 \\
128 X 128 X 1 \\
128 X 128 \times 128\end{array}$ & $\begin{array}{l}235 \mathrm{~ms} \\
1535 \mathrm{~ms} \\
21774 \mathrm{~ms}\end{array}$ \\
\hline
\end{tabular}




\section{VIRTUALIZATION AND VISUALIZATION}

Virtualization was invented more than 30 years ago to allow large, expensive mainframes to be easily shared among different application environments [40]. It could be understood as a technique to partition resources of a machine in multiple environments, creating a new level of indirection between physical resources and applications [41]. However, virtualization creates an abstraction environment between two computer resources; it also refers to running a virtual application that appears from the inside to be a real computer, but is actually being emulated on a real machine. It became popular in grid and cloud computing. The cloud could be with or without virtualization. Figure 1 shows the virtualization concept graphically.

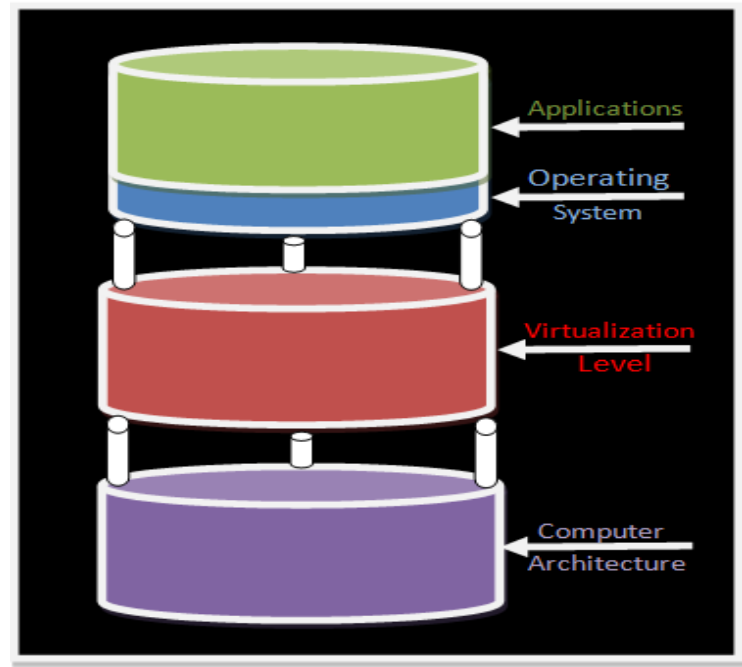

Figure1. Virtualization

Today, the term virtualization is widely applied to a number of concepts such as:

Server virtualization

- Client/Desktop/Application virtualization

- Network virtualization

- Storage virtualization

- Service/Application infrastructure virtualization

Visualization application is one of the most important communication applications. Visualization could be defined as converting data into graphics or images using computer software. It is also used to render screen images into three-dimensional (3D) models that can be viewed from all angles, and could be animated. Grid-based architectures might be suitable platforms for satellite and medical images, and graphical digital processing and analysis because they offer the required computational power to process in real time.

\section{TIME PROBLEM ANALYSIS}

Many problems could be noted and reported in using grid computing for visual applications. Throughout our survey which is used to identify potential problems with these applications and 
the grid itself. The problems could be classified into two main categories: the first one regards with the computation and transfer time while the second category regards with the display speed. Fang at al. [27] for example (see table 4 and 5), showed that the execution time for data size equals $400 \mathrm{k}$ is 23.83 seconds. This time is divided into 0.1093 seconds for data transfer, 23.5763 seconds for GPU and 0.1399 seconds CPU time. While the performance measurements of Wong et al. [37] (table 4 and 5) showed that GPU-based implementation achieves speedups of 2 (1D problem with 2048 grids), 106 (2Dproblem with 10242 grids), and 43 (3D problem with 1283 grids), respectively, compared to the corresponding serial CPU MHD implementation. The performance test showed that when the number of grids of the test problems is small, such as those in 1D case $(128 \mathrm{X} 1 \mathrm{X} 1 \ldots 2048 \mathrm{X} 1 \mathrm{X} 1)$, GPU MHD code could not give a significant performance improvement. This is because some processing time was spent when the initialized data and the necessary parameters were copied to the GRAM in the initialization status. When the number of grids increases, an obvious disparity of performance becomes clear, especially for multidimensional cases. On the other hand, rendering 50 slices of an image took 19 minutes using 7 homogeneous grid nodes [37].This time is high for rendering one image in real time. Besides that, the total run time of data set consists of 214 parameters is 220 min using grid computing Krefting et al [38] (table 4 and 5) and it is also very high to be used with real time rendering. The elapsed time is still high for real time data as pointed by [35] where, the approximate elapsed time is 270 seconds, for data resolution equals $4096^{\wedge} 3$ and volume equals $128 \mathrm{~GB}$.

Terzza and Djemame [42] used a dedicated test-bed for all rendering, comprising 2 Quad Core Xeon machines at $2.83 \mathrm{GHz}$ with $4 \mathrm{~GB}$ RAM each. For the cloud, the same test-bed set up was used with Open Nedula (an open source cloud computing implementation). Four VMs were run on each machine (one VM per core), each with 768 MB RAM.

POVRay (an open source ray tracing application) was chosen for tests along with a version patched for Message Passing Interface (MPI). Once each testing environment was set up, the rendering was run from a script that rendered images from 0.5 to $5 \mathrm{MP}$. Rendering was benchmarked with both POVRay and MPI POVRay run in several environments: from the command line on the test-bed, as a Globus Service using the Globus Toolkit, with and without $g$ rid security infrastructure file transfer protocol (GSIFTP) file staging, as a Web service using the Globus Toolkit, and finally as a Web service using Apache Tomcat and Axis. Terzza [42] showed that POVRay scales well with multiple cores (due to the embarrassingly parallel nature of the problem). Rendering tests on the grid and cloud showed that although not as fast as a "bare-bones" machine, their overhead is fair and they both perform with similar efficiency. Figure 2 illustrates the results graphically. 
International Journal of Computer Science \& Engineering Survey (IJCSES) Vol.2, No.4, November 2011

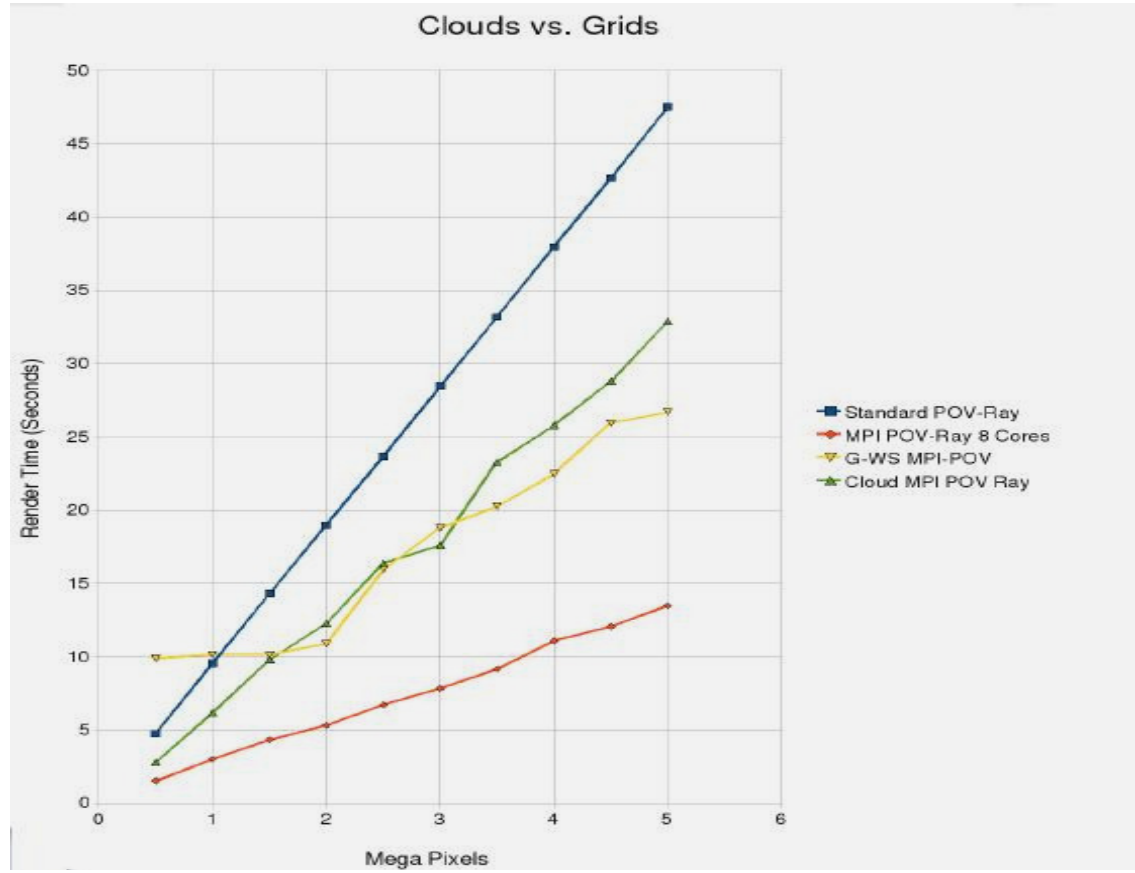

Figure2. Different render time clouds vs. grids [42]

Alexandre et al. [32] demonstrated some experiments to assess and compare the scalability of Jake2 and grid-based Jake2 (named Jake2Grid). In this context, it is important to determine the number of players a single game server could handle in real time (see Figure 4). MAC OS X Quad-Core Intel Xeon with 2.86 Ghz, 2 CPUs, 8 cores, 12 MB of L2 cache, 6 GB of memory, and $16 \mathrm{Ghz}$ of bus speed were used to run the server. One hundred other computers were used to run game clients. The scalability measurements of Jack2 versus Jack2Grid are shown in Figure 3 .

Jake2 VERSUS Jake2Grid

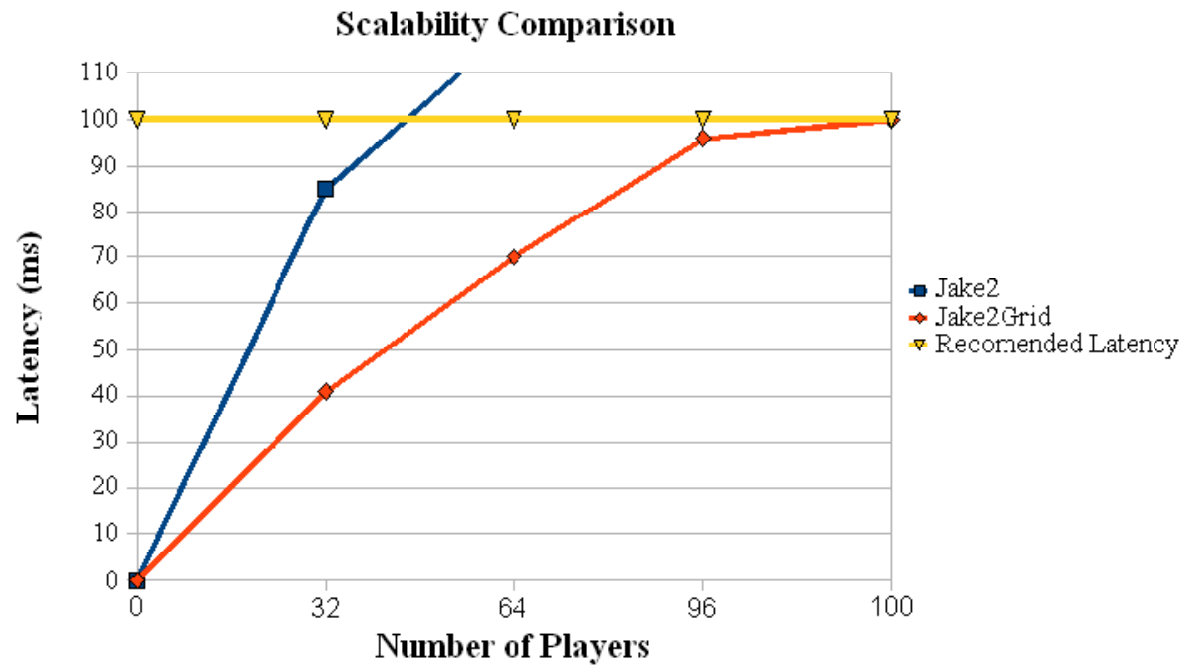

Figure3. Scalability measurements [32] 
However, although the elapsed time in the previous two examples improved using grid computing compared with traditional approaches, it is still high for real-time applications. Despite recent advances in accelerator technology, many real-time graphics applications still cannot run at acceptable rates.

\section{ADVANTAGES AND DISADVANTAGES}

Since time is measured in variant environments and conditions, and different data and processing are used, it is difficult to have a clear picture of the impact of time and communication speed factors on the performance of grid computing. However, it is important to address the potential advantages and disadvantages of using grid or cloud computing in different environments. Some advantages and disadvantages are obvious.

The main advantage of grid computing is more efficient use of idle resources because many resources sit idle especially during off business hours. Jobs are allowed only to communicate with servers that are lightly loaded or have the appropriate amount of memory/CPU characteristics. If one of the servers/personal computers (PCs) within the grid fails, other resources will pick the load. However, jobs can automatically restart if failure occurs. In addition, jobs can be executed in parallel speed performance where grid environments are extremely well-suited to run jobs that can be split into smaller chunks and can run concurrently on many nodes.

Transmitting large files over optical burst switching (OBS) grid networks results in poor performance primarily due to the many burst losses that will occur, as well as transmission control protocol (TCP) behavior due to these losses. Thus, a new adaptive assembly algorithm suitable for OBS grid networks involving large file transfers was presented by Korkakakis [43].

On the other hand, the use of grid and cloud computing especially with visual applications is limited by the following reasons.

1- It may need to have fast interconnection among resources' nodes, but various processors (e.g., PCs) on the Internet do not have high-speed connections. All results of all processes have to be sent from place to place and collaboratively assessed for any outcome to be deduced. This can be a strain in terms of timing issues as well as the fact that grid and cloud computing are heavily reliant on the ever-unpredictable notion of connectivity. The speed of the processors is different; thus, much is consumed waiting results.

2- It requires a stable Internet connection. Cloud computing is impossible if there is no connection to the Internet. A dead Internet connection means no work; in areas where Internet connections are few or inherently unreliable, this could be a deal-breaker. It does not work well with low-speed connections. Similarly, a low-speed Internet connection such as dial-up services makes cloud computing painful at best and often impossible. Web-based apps require much bandwidth to download; cloud computing is not for the broadband-impaired. Even on a fast connection, Web-based applications can sometimes be slower than accessing a similar software program on desktop PCs. Everything about the program, from the interface to the current document, has to be sent back and forth from the computer to computers in the cloud. If the cloud servers happen to be backed up at that moment, or if the Internet is slow, instantaneous access will not be the same as with desktop apps. Stored data might not be secure and can be lost. 
International Journal of Computer Science \& Engineering Survey (IJCSES) Vol.2, No.4, November 2011

\section{CONCLUSIONS AND FUTURE WORK}

Grid or cloud computing is used effectively to advance image processing and analysis. For example, medical image applications and game playing need high-speed rendering especially when used in a real time. Grid or cloud computing is suitable technology to solve problems that require intensive processing, and was believed capable of flexibly coping with visual real-time applications like game playing. The real bottleneck in using grid or cloud computing in such applications is whether the communication time between nodes (inside the cloud) increases to the point of degrading overall application performance. The main technological challenges that can be identified and that are commonly associated with visual cloud systems are virtualization and data Management which are described throughout this paper. We analyze the impact of time and communication speed problem on applying visual systems on grid and cloud computing. Future work should focus on this problem with a new selection approach of parallel methods of applications and their distribution over the grid nodes or the cloud.

\section{ACKNOWLEDGEMENTS}

The authors wish to express their gratitude to the FSKTM -UM staff for their financial support. The authors would also like to thank the anonymous editors and editor-in-chief for advice and helps with this paper.

\section{REFERENCE}

[1] Yang, J., Shi, J., Jin, Z., and Zhang, H., Design and Implementation of a Large-Scale Hybrid Distributed Graphics System. In Proceedings of the Fourth Eurographics Workshop on Parallel Graphics and Visualization. ACM, 2002, pp. 39-49.

[2] Andrews, G. R. ,Foundations of Multithreaded, Parallel, and Distributed Programming, AddisonWesley, ISBN0-201-35752-6, 2000.

[3] Almasi, G. S. and Gottlieb,A., Highly Parallel Computing. Benjamin-Cummings publishers, Redwood City, CA, 1989.

[4] An Oracle White Paper in Enterprise Architecture ,"Architectural Strategies for Cloud Computing", August 2009.availableonline at:

http://www.oracle.com/technology/architect/entarch/pdf/architectural_strategies_for_cloud_computing.pd $\mathrm{f}$

[5] Foster, I.,Kesselman, C., and Tuecke, S. 2001. The anatomy of the grid Enabling Scalable Virtual Organizations. Intl. J. Supercomput. Appl.

[6] Adabala, S., Chadha,V., Chawla,P., Figueiredo,R., Fortes,J., Krsul,I., Matsunaga, A., Tsugawa,M., Zhang,J., Zhao,M., Zhu,L., and Zhu,X., From Virtualized Resources to Virtual Computing Grids: The In-VIGO System, Future Generation Computer Systems, vol. 21, June 2005, pp. 896909.

[7] Jacob, B. , Brown M. , Fukui K. , Trivedi N. ,Introduction to grid computing An IBM Redbooks publication,2005. Available online:

http://www.redbooks.ibm.com/redbooks/pdfs/sg246778.pdf

[8] Lakshmi kanna M G, Ravichandran K S, "Image Transformation using Grid", GVIP Journal, Volume 6, Issue 4, December, 2006

[9] Editor: Mark Linesch, HP, rid - Distributed Computing at Scale. An overview of Grid and the Open Grid Forum, August 28, 2007. 
International Journal of Computer Science \& Engineering Survey (IJCSES) Vol.2, No.4, November 2011

[10] Wang, L., Laszewski, G. , Tao, J., and Kunze, M., Provide Virtual Machine Information for Grid Computing, IEEE Trans. on SMC (TSMC), 2010.

[11] Bechtolsheim,A., cloud computing, Chairman \& Co-founder, Arista Networks November 12th, 2008.

[12] Armbrust,M., Fox, A., Griffith,R., Joseph,A., Katz,R., Konwinski,A., Lee,G., Patterson,D., Rabkin,A., Stoica,I., Zaharia,M., Above the Clouds: A Berkeley View of Cloud computing. Technical Report No. UCB/EECS-2009-28, University of California at Berkley, USA, Feb. 10, 2009.

[13] Gillis,M., Cloud Computing Expanding IT flexibility and agility, ICT Spring Event Europe Luxemburg, March 2010.

[14] F5 Networks, Cloud Computing Survey: June - July 2009.

[15] Vaquero,L., Rodero-Marino,L., Caceres,J., Lindner,M., A break in the clouds: towards a cloud definition, SIGCOMM Computer Communication Review, vol. 39 ,2009, pp. 137-150

[16] Mell,P., and Grance,T., Draft NIST working definition of cloud computing, Referenced on June. 3rd, 2009 Online at: http://csrc.nist.gov/groups/SNS/cloud-computing/index.html.

[17] Buyya,R., Yeo, C. S. , Venugopal, S. Broberg, J. andBrandic, I., Cloud Computing and Emerging IT Platforms: Vision, Hype, and Reality for Delivering Computing as the 5th Utility. Future Generation Computer Systems, Elsevier Science, Amsterdam, The Netherlands, vol. 25 ,issue 6, June 2009, pp. 599-616,

[18] F5 white paper, F5 Networks' perspective on cloud computing: definition, architecture, and development, Lori MacVittie ,Alan Murphy ,Peter Silva ,Ken Salchow, www.f5.com, 2010.

[19] Application note ADVA optical networking, "Optical networks for cloud and grid computing", May, 2009, available online at:

http://www.advaoptical.com/ApplicationNotes/2009/AN_Optical_Networks_Grid_Cloud.pdf

[20] Buyya, R., Ranjan, R. and Calheiros, R.N., Modeling and Simulation of Scalable Cloud Computing Environments and the CloudSim Toolkit: Challenges and Opportunities, Keynote Paper. In: Proceedings of the 7th High Performance Computing and Simulation (HPCS 2009) Conference, Leipzig, Germany,June, 2009.

[21] Das,S., Agrawal,D. and El Abbadi,A., ElasTraS: An ElasticTransactional Data Store in the Cloud. In USENIX HotCloud,2009.

[22] Wei, Z., Pierre,G., and Chi, H., CloudTPS: Scalable transactions for Web applications in the cloud. Technical Report IR-CS-053,VrijeUniversiteit, Amsterdam, The Netherlands, February 2010. Available on line: http://www.globule.org/publi/CSTWAC_ircs53.html

[23] Huang, X., Huang,L., and Li, M., Grid-enabled medical image processing application system based on OGSA-DAI techniques, Apweb workshop 2006, pp.460-464.

[24] Oliveira,M. C.,Cirne,W ,Junior, J. F. M, Marques,P., Grid computing to make viable the content based medical images retrieval through the image registration techniques, Euro American Conference On Telematics And Information Systems archive Proceedings of the 2007 Euro American conference on Telematics and information systems table of contents Faro, Portugal SESSION: Full papers table of contents Article No.: 16 ,2007, ISBN:978-1-59593-598-4

[25] Shen,Z., Luo,J., Huang,G., Ming,D., Ma,W., and Sheng,H., Distributed computing model for processing remotely sensed images based on grid computing, Information Sciences, Vol.177, Issue 2, 15, Jan. 2007, pp.504-518.

[26] Akhter,Sh.,Osawa,K., Nishimur,M., and Aida,K., Experimental Study of Distributed SWAP-GA Models on the Grid, IPSJ Transactions on Advanced Computing Systems Vol. 1 No. 2, Aug. 2008, pp. 193-206. 
International Journal of Computer Science \& Engineering Survey (IJCSES) Vol.2, No.4, November 2011

[27] Fang,W., Lau,K. K., Lu, M., Xiao, X., Lam, C. K., Yang, P. Y., He, B., Luo,Q., Sander , P. V.,Yang, K., Parallel Data Mining on Graphics Processors, Technical Report HKUSTCS0807,Oct 2008.

[28] Lesage, J. D., and Raffin,B., A hierarchical component model for large parallel interactive applications, LLC J Supercomput, 2008, DOI 10.1007/s11227-008-0228-7

[29] McGuigan,M., Toward the Graphics Turing Scale on a Blue Gene Supercomputer, arXiv:0801.1500v1 [cs.GR] 9 Jan 2008.

[30] Polak,M. and Kranzlmüller,D., Interactive video streaming visualization on grids, Future Generation Computer Systems, Vol. 24, Nr. 1, Amsterdam, The Netherlands, January 2008,pp. 39-45,

[31] Xu,X., and Taylor,V., Performance Analysis of Parallel Visualization Applications and Scientific Applications on an Optical Grid, Proceedings of the 2008 International Conference on Cyberworlds, China, September 22-24,2008, Pages: 447-454, ISBN:978-0-7695-3381-0.

[32] Alexandre,R., Prata,P. and Gomes,A., A Grid Infrastructure for Online Games, ICIS, November 24-26,seoul Korea, 2009.

[33] Bektaş,K., and Çöltekin,A., A Survey of Stereoscopic Visualization Support in Mainstream Geographic Information Systems, Proceeding, True 3D cartography, 1st International conference on 3DMaps,Aug,24-28 Dresden, Germany, 2009.

[34] Eilemann,S., Makhinya,M. and Pajarola,R., Equalizer: A Scalable Parallel Rendering Framework, IEEE Transactions On Visualization And Computer Graphics, Vol. 15, No. 3, May/June 2009.

[35] Nishihashi,K., Higaki,T., Okabe,K, Raytchev,B., Tamaki,T. and Kaneda,K., Volume rendering using grid computing for large - scale volume data, Proceedings of 11th IEEE International Conference on Computer-Aided Design and Computer Graphics, Huangshan, China , 19-21 August, 2009, page.470-477.

[36] Zhurong,Z., Wei,D., Yuhui, Q. and Linrui,L., A Grid Based Graphics Rendering Design, International Forum on Information Technology and Applications, China, 15-17, May 2009.

[37] Wong, H. Ch.,Wong,U. H., Feng, X. and Tang,Z., Magnetohydrodynamics simulations on graphics processing units, Journal of Computational Physics ,2009.

[38] Krefting,D., Vossberg,M., Hoheisel,A., and Tolxdorff,T., Simplified implementation of medical image processing algorithms into a grid using a workflow management system, Future Generation Computer SystemsVolume 26, Issue 4,April,2010,, Pages 681-684.

[39] Riedel, M., Frings,W., Eickermann,Th., Habbinga,S., Gibbon,P., Streit,A., Wolf,F., and Lippert,Th., Collaborative Interactivity In Parallel Hpc Applications, Interactive Computational Steering of Grid Applications, In Proc. of the Instrumenting the Grid (InGrid) Workshop, LaccoAmeno, Island of Ischia, Italy, Springer, January 2010, pp. 249-262.

[40] Menasce, D. , and Bennani, M., Autonomic Virtualized Environments, In Proc. International Conference on Autonomous Systems (ICAS'06), Silicon Vally, CA,July 19-21,2006.

[41] Benevenuto,F., Fernandes, C.,Santos,N., Almeida,V., Almeida,J., Janakiraman,G.,andSantos,J., erformance Models forVirtualized Applications ISPA 2006, LNCS 4331, p.427-439.

[42] Terzza,M. and Djemame ,K., Cloud Computing and its application to Image Processing, School of Computing, Summer Internship 2009.

[43] Korkakakis, N., Vlachos, K.: An adaptive burst assembly scheme for OBS-GRID networks, In: Proc. of 6th International Symposium on Communication Systems, Networks and Digital Signal Processing (CNSDSP), Graz, Austria, 25 July 2008, pp. 414-417. 


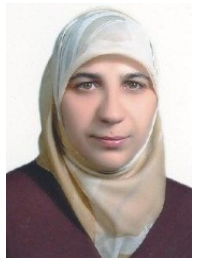

Dr. AlaaYaseenTaqa has received her master degree on Computer Science, M.SC. on Applied Object-Oriented Software Engineering Methodology for industrial systems, from NCC,2001, Iraq and her Ph.D. in Computer Science, on anti-spam filters, Mosul University,2007,Iraq. Her interest research area on pattern recognition,artificial intelligence, anti-spam systems, steganography, textual and visual applications and finally cloud computing. Dr. Alaa job title is lecturer at university of Mosul, she was appointed as a visiting researcher at the faculty of computer science and information technology at University Malaya(UM),2010.

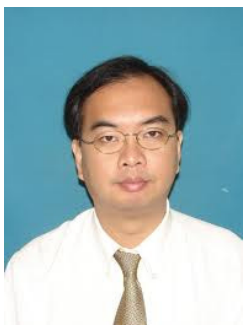

Dr. Ng Liang Shing received his BEng(Hons) in Electronic Engineering in 1995 and $\mathrm{PhD}$ in the area of image processing in 1999, both from the University of Southampton, United Kingdom. He is currently a Senior Lecturer at the Department of Artificial Intelligence, Faculty of Computer Science \& Information Technology- University of Malaya. His research interests include artificial intelligence, robotics and simulation. His research team currently works on projects on large scale and detailed simulation of the real world, a unified framework to represent physical processes and natural languages, simulation of gold and silver as currencies and simulation of the effect of the bazaar system on macro-economy.

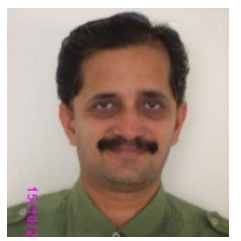

Dr. Ajay Joshi joined the department of electrical and computing engineeringThe University of the West Indies in 2007. He received his BS (major Electronics) from the University of Bombay in 1984, his D.F.T. from the board of Technical education Bombay 1986 and his Ph.D. from the University of Mumbai in 1997. 